\title{
O episódio de Freud com a cocaína: o médico e o monstro*
}

Decio Gurfinkel

O objetivo do trabalho é uma avaliação dos possíveis "restos" que o episódio de Freud com a cocaína tenha deixado para a criação da psicanálise, realizada através do reexame retrospectivo, crítico e analítico desse episódio. O resultado desta avaliação pôs em destaque quatro elementos: o surgimento de um Freud psiquiatra e farmacologista e o progressivo abandono desta via; o surgimento da adicção como objeto de investigação; o modelo da autoadministração como método de pesquisa; e a crença e abandono subseqüente de um projeto de "cura mágica".

Palavras-chave: Freud, cocaína, história da psicanálise, adicções

* Este artigo é parte de uma pesquisa de Pós-Doutorado realizada no Programa de Estudos PósGraduados em Psicologia Clínica da PUC-SP, com apoio da FAPESP (processo n. 05/58749-0). 
Após ter criado a psicanálise, Freud nunca dedicou um ensaio ao estudo das adicções; como sabemos, o primeiro trabalho inteiramente dedicado ao tema foi de Abraham (1908). Antes disto, no entanto, quando era um jovem médico, ele escreveu uma longa monografia e alguns pequenos artigos sobre a cocaína, tendo estado bastante envolvido com a droga ao longo de alguns anos. Acompanhando a sua obra posterior, notamos sinais seguros de que a adicção e as drogas não escaparam à sua atenção e, mais do que isto: podemos ler, nas entrelinhas, elementos essenciais de uma concepção psicanalítica sobre as adicções (cf. Gurfinkel, 1996). Ainda assim, a ausência de um trabalho de Freud sobre o tema não deixa de intrigar o leitor atento. Se ele teve a preocupação de cobrir ao máximo o campo da psicopatologia e de expandir suas reflexões para os mais diversos campos, por que esta lacuna?

A pergunta dá margem a especulações. Uma das possíveis respostas encontra-se no envolvimento de Freud com a cocaína; será que o chamado "episódio da cocaína" (segundo Jones) contribuiu para um relativo silêncio sobre o tema nos anos seguintes? O objetivo deste artigo é examinar as repercussões desse episódio, que possivelmente deixou como "resto" algumas elementos que marcaram a criação da psicanálise.

O “episódio da cocaína” é, em geral, pouco conhecido, e recheado de controvérsias; Freud (1924) mesmo mencionou-o de modo muito ligeiro na sua "Autobiografia", dedicando-lhe um único parágrafo. Sabe-se que o jovem Freud era um pesquisador apaixonado e dedicado, e que ambicionava realizar uma "grande descoberta"; tratava-se de uma ambição intelectual que se entrelaçava com uma ambição pessoal: necessitava conseguir uma estabilidade financeira mínima para poder casar-se com sua amada Martha. Após algumas tentativas frustradas, deparou-se com um alcalóide quase desconhecido que, conforme lhe pareceu, prometia se tornar a tal "descoberta". Mergulhou febrilmente na bibliografia e iniciou diversas experiências com o uso da droga em si mesmo e em outros (amigos, parentes e pacientes). A sua monografia "Sobre a coca", de 1884, é um estudo meticuloso e entusiástico sobre a história da droga, seus efeitos e possíveis usos terapêuticos. Dentre as controvérsias que cercam o episódio da cocaína, encontra-se o doloroso episódio de um colega e amigo (Koller) que teria

Rev. Latinoam. Psicopat. Fund., São Paulo, v. 11, n. 3, p. 420-436, setembro 2008 
"roubado" a fama por publicar em seguida um trabalho sobre os efeitos anestésicos da cocaína; a história trágica de outro amigo (Fleischl) cujo vício em morfina Freud incentivou a tratar com uso de cocaína e que acabou morrendo, assim como o grau de envolvimento pessoal de Freud com a droga em termos do uso da mesma.

O "episódio" tem sido discutido por diversos autores (Bernfeld, 1975; Jones, 1989; Scheidt, 1975; Gay, 1989; Cesarotto, 1989 e Rodrigué, 1995), e não será retomado em detalhes. Abordarei, aqui, as repercussões que sobrevieram nos anos seguintes à publicação de "Sobre a coca", acompanhando os artigos de Freud sobre a cocaína que se seguiram à primeira monografia.

\section{Após "Sobre a coca"}

Quando Freud iniciou seus experimentos com a droga e distribuiu-a para diversos colegas, alguns deles relataram sucesso com seu uso, enquanto outros mostraram-se mais reticentes. Este foi o caso de Breuer, "pai" profissional de Freud. A sua conhecida cautela mostrou-se justificada: pouco tempo depois, foi ele quem acompanhou a agonia de Fleischl como seu médico. Após a publicação do trabalho de Koller, Freud continuou a fazer experiências de uso da cocaína para tratar de várias doenças. Procurou aplicá-la em casos de diabetes e de enjôo marítimo, obtendo algum resultado positivo neste último caso; um pouco depois, testou a cocaína em casos de hidrofobia. Ao mesmo tempo, recebeu muitas congratulações da comunidade médica pelo seu trabalho.

Freud estava igualmente intrigado com a irregularidade dos efeitos da cocaína nos diversos pacientes, já que os relatos de experiências divergiam bastante. Desta forma, era difícil desenvolver seu emprego clínico. Procurou, então, em seu artigo seguinte ("Contribuição ao conhecimento da ação da cocaína", 1885b), auferir a ação da droga de maneira objetiva, através do método experimental. Utilizando o dinamômetro e o neuramebímetro, colheu observações - novamente em si mesmo - sobre a capacidade muscular e a presteza das reações sob o efeito da cocaína. As conclusões foram interessantes: os efeitos da cocaína só se mostraram significativos em pacientes cansados ou deprimidos, do que se depreende que a cocaína não tem ação direta sobre o sistema neuromuscular; as alterações nesse sistema são secundárias ao bem-estar artificial produzido pela droga.

A sua monografia ganhava alguma divulgação, especialmente com a publicação de um artigo nela baseado. Um laboratório americano que estava começando a sintetizar a droga contratou-o para testá-la, redundando em um informe de 
Freud que confirmava a qualidade da droga, e previa para o preparado de Parke "um grande futuro" (Guttmacher, 1885, p. 123).

Mas o trabalho mais relevante veio a seguir. Freud foi convidado a fazer duas conferências sobre a cocaína (no Clube de Fisiologia e na Sociedade Psiquiátrica), que constituíram uma nova publicação: "Sobre os efeitos gerais da cocaína" $(1885 c)$. Nesse trabalho, Freud assinalou como existiam então drogas destinadas a reduzir a excitação nervosa (à maneira de ansiolíticos), mas poucos métodos para elevar a atividade psíquica (estimulantes do sistema nervoso central); esta seria, para ele, a promessa da cocaína para o campo da psiquiatria e do tratamento das doenças nervosas.

\section{Contribuições para a psiquiatria}

Essa conferência dirigida aos psiquiatras nos mostra o papel cumprido por Freud na história da psicofarmacologia. Robert Byck (1974), professor de farmacologia psiquiátrica, ao tomar contato com os artigos de Freud sobre a cocaína, deu-se conta de imediato que "eles colocam Sigmund Freud como um dos fundadores da psicofarmacologia" (p. xvii). A busca de uma droga estimulante para tratar a melancolia continuou na ordem do dia, e apesar da cocaína ter sido suplantada pela medicina como droga terapêutica, o método de pesquisa rigoroso e os princípios subjacentes à investigação de Freud sobre a cocaína são equivalentes, segundo Byck, aos de outros pioneiros que aventuraram-se no estudo de drogas psicoativas tais Moreau de Tours, Hofmann e Alles.

Em "Sobre a coca", Freud (1884) já havia chamado a atenção para uma lacuna no arsenal psiquiátrico que a cocaína poderia vir a preencher:

... é fato conhecido que os psiquiatras dispõem de um amplo suprimento de drogas para reduzir a excitação dos centros nervosos, mas nenhuma que poderia servir para incrementar o funcionamento rebaixado desses centros. A cocaína tem sido receitada, neste sentido, para os mais variados distúrbios psíquicos: histeria, hipocondria, inibição melancólica, estupor e outros quadros similares. (p. 64)

Freud cita, em seguida, relatos de diversos tratamentos bem-sucedidos em casos de hipocondria, neurastenia, prostração nervosa, histeria e melancolia, e conclui: "a eficácia da coca em casos de distúrbios nervosos e psíquicos necessita investigações ulteriores, que provavelmente conduzirão a conclusões parcialmente favoráveis" (p. 65). No ano seguinte, diante dos psiquiatras, Freud (1885c) propôs que a aplicação da cocaína se destinava a "formas de doenças que interpretamos como estados de debilidade e de depressão do sistema nervoso, sem

Rev. Latinoam. Psicopat. Fund., São Paulo, v. 11, n. 3, p. 420-436, setembro 2008 
lesão orgânica"não consta na biblio (p. 116), mencionando novamente os quadros de histeria, hipocondria e melancolia. Ele volta a dizer, por fim, que a utilidade terapêutica da droga na psiquiatria necessita ainda comprovações, mas que se justifica o empreendimento de "amplas investigações" sobre o assunto.

Além do uso da cocaína para tratar distúrbios psíquicos, Freud propõe uma segunda aplicação de interesse para a psiquiatria, já apresentada na monografia de 1884: o uso da droga para tratar o vício em morfina. Agora, porém, ele reconhece que o sucesso não se dá igualmente em todos os casos, e reitera que não observara casos de vício em cocaína. Em "Sobre a coca", Freud (1884) afirmara que "uma primeira dose ou repetidas doses de coca não produzem o desejo compulsivo de seguir usando o estimulante; ao contrário, experimenta-se uma certa aversão injustificada à substância" (p. 62). Ora, no mês seguinte às conferências (abril de 1885), ele passou a primeira noite de martírio ao lado de Fleischl, e constatou que ele tomava doses enormes de cocaína - cem vezes a quantidade que ele mesmo, Freud, tomava, e apenas de vez em quando. Nos dois meses seguintes, Freud passou várias noites testemunhando o "profundo desespero" de Fleischl, vendo de perto o mal que a droga lhe causava: desmaios e convulsões, grave insônia e comportamento extravagante. Instalou-se, então, uma ebriedade crônica e o delirium tremens. $\mathrm{O}$ artigo foi publicado em agosto.

Como podemos notar, Freud mostra aqui uma consciência plena dos dois principais âmbitos de interesse potencial da psiquiatria pelas drogas psicotrópicas. Em primeiro lugar, tais drogas interessam enquanto remédios destinados a sanar algum tipo de desequilíbrio psíquico - e Freud viu na cocaína exatamente aquilo que a psiquiatria tem incansavelmente buscado nos chamados antidepressivos. E, em segundo lugar, as drogas vieram a se tornar uma preocupação crescente da psiquiatria devido seu potencial abuso e vício, dando origem a um quadro psicopatológico cada vez mais freqüente: a toxicomania. Este é - irônica e paradoxalmente - uma espécie de "efeito colateral" do feitiço das drogas mágicas, que pode se voltar contra o aprendiz de feiticeiro. Apesar de seus tropeços e precipitações, é inegável que mais uma vez aqui ele foi movido por uma intuição e por um discernimento visionários.

Ora, ao lado da difusão das pesquisas sobre a cocaína - e quase ao mesmo tempo - começaram a surgir os problemas e as primeiras críticas.

Erlenmeyer foi um dos primeiros e mais mordazes críticos de Freud. Mas a questão não mostrou-se tão pessoal, pois ao longo de 1886 surgiram relatos de casos de vício em cocaína e de ebriedade devido à droga oriundos de várias partes do mundo (apud Jones, 1989). Mesmo Obersteiner (apud Jones, 1989), defensor ardoroso de Freud que ressaltou o valor da cocaína durante a retirada da morfina, veio a reconhecer em um segundo momento que o uso continuado 
da cocaína podia levar ao delirium tremens. O ponto alto desse movimento crítico encontra-se na denominação, por Erlenmeyer, da cocaína como "o terceiro flagelo da humanidade", ao lado da morfina e do álcool.

O homem que tentara beneficiar a humanidade ou, em todo caso, criar a reputação através da cura de "neurastenia" era agora acusado de desencadear o mal pelo mundo. Muitos devem tê-lo olhado pelo menos como um homem imprudente em seus critérios. E se sua sensível consciência formulou a mesma sentença, ela seria confirmada por uma triste experiência um pouco posterior, quando, supondo que se tratava de uma droga inócua, recomendou uma grande dose dela a uma paciente que em conseqüência veio a sucumbir. (Jones, 1989, p. 104)

Em "Sobre a coca", além de negar a adicção à cocaína, Freud minimizara os riscos de alta dosagem, citando o caso de um químico que tentara se envenenar com a cocaína e apenas passara mal, com sintomas de gastroenterite; e, ao refutar os "temores injustificados" das autoridades quanto a injeções de cocaína no "Adendo" de 1885, foi bastante taxativo: "para os humanos, a dosagem tóxica é muito alta, e não parece haver dose letal" (1885a, p. 109). Bem, não é necessário lembrar o risco hoje conhecido da overdose de cocaína, especialmente entre os viciados que dificilmente distinguem o que seria uma "dose muito alta". Segundo Jones, é difícil avaliar se e o quanto estes acontecimentos afetaram a reputação de Freud em seu meio social e científico; ele mesmo, no entanto, declarou posteriormente que o episódio acarretara "graves censuras".

Freud demorou para defender-se de tais críticas. Em 1887, publicou "Observações sobre a adicção e o medo da cocaína", último de seus artigos sobre o tema, no qual buscou se posicionar diante dos novos desdobramentos. Nele, Freud começa por assinalar que as propriedades anestésicas da cocaína eclipsaram o que seria o seu uso mais promissor: no tratamento dos distúrbios nervosos. Em seguida, dedica-se a refutar as críticas de Erlenmeyer e certas observações de especialistas em garganta e olhos a respeito dos efeitos tóxicos da cocaína, e apóia-se, ao mesmo tempo, nos estudos a ele favoráveis de Obersteiner e Hammond (apud Jones, 1989). Freud vislumbra, ainda, a ponta de um enorme iceberg que viria a emergir no século XX: a cocaína chamara a atenção não só dos médicos interessados no seu valor no tratamento do vício em morfina, mas também - e "lamentavelmente" (sic) - dos próprios morfinômanos. Ou seja: as "drogas mágicas" descobertas e disseminadas pelo saber médico são sempre passíveis de tornarem-se objeto de um "mau uso" nas mãos de "espíritos mais doentios"...

Freud argumentou que o perigo visto por Erlenmeyer na cocaína deveu-se a um "grave erro experimental", já que este "desobedecera" à sua recomendação quanto à dosagem e utilizara a droga pela via subcutânea. Jones ressaltou, com 
razão, que esse argumento tinha pouca consistência, e contrariava afirmações anteriores que o próprio Freud buscava agora encobrir - provavelmente de modo inconsciente. Assim, ao propor o uso da cocaína no tratamento de morfinômanos na conferência para os psiquiatras, Freud (1885c) fora bastante taxativo: "de acordo com toda informação que consegui coletar até este momento, só me resta recomendar, sem hesitação [itálico meu], injeções subcutâneas de 0,03 a 0,05 gramas em tais curas de abstinência, sem nenhum medo do aumento da dosagem" (p. 117). Ora, esse último artigo foi, em 1887, suprimido pelo próprio Freud de uma lista de trabalhos seus que teve que preparar quando requereu o título de professor. E ainda: para reafirmar o constrangimento de Freud com a sua recomendação de injeções em 1885, Jones mencionou um lapso de datas - anteriormente ressaltado por Bernfeld - no qual Freud trocara em sucessivas reedições de $A$ interpretação dos sonhos o ano de sua monografia sobre a cocaína para 1885. Ao comentar a confusa defesa de Freud em relação a Erlenmeyer, Jones ressaltou que, na época, havia um grande preconceito contra injeções hipodérmicas, e lembrou também o significado simbólico das injeções no psiquismo inconsciente. " "Ao procurar afastar de sua substância mágica o estigma de ser uma perigosa droga, Freud apelaria para o preconceito geral, dando a entender que as injeções hipodérmicas eram o perigo real" (Jones, 1989, p. 105). Creio, porém, que para além do significado simbólico geral das injeções e dos preconceitos da época - em relação aos quais, aliás, não era do feitio de Freud se curvar -, podemos avançar mais na nossa investigação se considerarmos o sentido singular das injeções na experiência de Freud, como temos notícias pelo sonho da injeção de Irma.

\section{A adicção como objeto de investigação}

Mas nesse último artigo do ciclo de trabalhos sobre a cocaína, encontramos um segundo argumento de defesa, muito mais promissor: Freud levanta de modo mais explícito o problema da idiossincrasia do sujeito que se droga. Reconhecendo que havia reações muito diferentes para cada usuário, e que de fato muitos morfinômanos se tornaram cocainômanos, nosso pesquisador ressaltou a irregularidade dos efeitos da cocaína, atribuindo-a a um fator predisposicional.

1. Abraham (1908) propôs, em seu artigo pioneiro, que quando se aplica uma injeção hipodérmica de morfina ou outra substância em um paciente insano, ele "a considera como um ataque sexual, e interpreta a seringa e o fluido de maneira simbólica” (p. 67). 
"Desconfio de que a razão da irregularidade do efeito da cocaína repousa nas variações individuais de excitabilidade e na variação da condição dos nervos vasomotores sobre os quais atua" (Freud, 1887, p. 175). Como se vê, a predisposição é aqui tratada em termos fisiológicos e neurológicos; ora, um dos debates dos estudos sobre adicção refere-se a tal fator predisposicional: existe uma predisposição para a adicção? Em caso afirmativo, trata-se de um fator fisiológico, neurológico ou psíquico? Diversos psicanalistas têm se dedicado a compreender os fatores psíquicos da predisposição à adicção. Freud, ao criar a psicanálise, abriu caminho para uma outra dimensão do predisposicional, orientando a investigação do psíquico para um caminho diferente da psiquiatria predominantemente organicista; neste sentido, podemos observar o salto qualitativo que estava ainda por vir.

Ainda assim, é notável o avanço implicado no deslocamento de abordagem da droga em si mesma para o sujeito que se droga. "A cocaína, por si mesma, nunca produziu uma vítima" (p. 173). Não creio que aqui se dê apenas uma defesa enviesada da inocência da droga-ré, com quem Freud estaria identificado: podemos entrever também uma descoberta e um esboço de elaboração de um princípio metodológico fundamental. Freud reconheceu que certos usos da cocaína podiam ser bem perniciosos, como no caso de morfinômanos que vieram a "abraçar a nova causa". Nesses casos,

... no lugar de um marasmo lentificado, observamos uma rápida deterioração moral e física, estados alucinatórios e agitação similar ao delirium tremens, mania de perseguição crônica caracterizada, na minha experiência, pela alucinação de pequenos animais movendo-se na pele, e a troca da adicção à morfina pela adicção à cocaína - tais foram os tristes resultados de querer exorcizar o diabo por intermédio de Belzebu. (p. 172)

Ora, neste sentido, diabo não está na droga, e sim no (mau) uso da mesma; deve-se, portanto, cuidar de não tratá-la como um "agente do mau", ${ }^{2}$ e sim procurar o diabo, ao invés disto, no lado do sujeito que se droga - em sua idiossincrasia, em uma predisposição ou em um funcionamento adictivo já instalado. Ou seja: é preciso se debruçar sobre o enigma da adicção. A psicanálise nos fornece sem dúvida instrumentos poderosos para avançar nesta pesquisa.

Assim, se atentarmos para o título do artigo de Freud, podemos observar que nele se dá um deslocamento de objetivos e de objeto de pesquisa que não deve

2. Atribuir um poder maligno ao objeto-droga já é, como indiquei em outro lugar - "A droga e a coisa" (Gurfinkel, 2001) -, o resultado de uma distorção na relação sujeito-objeto característica dos adictos; ora, tal distorção também é, muitas vezes, compartilhada por aqueles que o cercam: os familiares e as comunidades social e "científica". 
ser menosprezado: agora o objeto não é prioritariamente a cocaína em si mesma, mas o problema da adicção ou da aversão a ela. Segundo este ponto de vista, podemos considerar este trabalho o primeiro ensaio freudiano em que se empreende uma reflexão sobre as adicções. À medida que ultrapassamos o espírito de Idade Média que trata droga como a bruxa a ser queimada, surge - ao lado do enigma da adicção - uma outra questão a ser problematizada: a aversão sistemática, demonização ou fobia em relação à droga. Freud entreviu no movimento que se erguia contra a cocaína uma reação também patológica, o outro lado da moeda da defesa apaixonada dos viciados. Alguns anos depois, em trabalho pioneiro, Ferenczi (1911a) veio a denunciar a falácia do anti-alcoolismo: "a atividade de agitação partidária dos antialcoólicos tenta esconder o fato de que o alcoolismo é apenas uma das conseqüências, certamente grave, mas não a causa, das neuroses" (p. 160, nota de rodapé). E, em outro trabalho, lembrando que "a responsabilidade dos sintomas de embriaguez não incumbia, em nenhum caso, somente ao álcool" (p. 175), Ferenczi (1911b) viu no anti-alcoolismo uma reação neurótica: o zelo excessivo, o ascetismo e a recusa do álcool seriam derivados de pulsões sexuais recalcadas que, associadas à culpabilidade, reclamam uma punição pela privação. Ou seja: tratar-se-ia de uma hipermoral reativa e neurótica. É digna de nota a semelhança fonética dos termos alemães que, no original, designam no artigo de 1887, a adicção e o medo da cocaína: Cocaïnsucht e Cocaïnfurcht. Considerando-se as observações de Freud (1910) sobre o duplo sentido antitético das palavras primitivas, poderíamos supor que se trata, de fato, de dois lados de uma mesma moeda? Adicção e medo: a irresistível força de atração e a irresistível força de repulsão em relação ao objeto - força centrípeta e força centrífuga.

Creio que podemos observar, neste desfecho "oficial" do episódio da cocaína, um amadurecimento significativo da relação de Freud com a droga. Do ponto de vista científico, notamos um movimento de abertura com a colocação em questão do enigma da adição e de seu contraponto, a aversão à droga. No entanto, não se deve esquecer que se trata, de fato, de uma abertura inicial, já que grande parte dos instrumentos de pensamento para dar conta de tais questões ainda estavam por vir; a explicação fisiológica e neurológica da predisposição é um bom exemplo de tal limitação. Do ponto e vista subjetivo, podemos supor que Freud viveu um refreamento, modulação ou "esfriamento" de suas ambições e de suas expectativas exageradas depositadas na droga; também ele precisava deslocar-se e desfascinar-se de tal objeto mágico. Foi preciso reconhecer os riscos envolvidos no seu uso, e ser mais prudente: "considero recomendável abandonar, na medida do possível, o uso de injeções subcutâneas de cocaína no tratamento dos distúrbios nervosos internos" (p. 175), mas sem "jogar fora o bebê com a água”: 
“os efeitos tóxicos não devem nos levar a descartar a aplicação de cocaína para obter o fim almejado" (p. 174). É claro que temos ainda aqui um reconhecimento parcial, uma vez que o "mal/mau" fica projetado e atribuído às seringas; esta confusão de responsabilidades é mais um reflexo do processo de elaboração da culpabilidade, que possivelmente prejudicava o seu discernimento científico.

\section{A auto-administração e a queda da panacéia: lições para o futuro} nálise?

Quais lições Freud levou do "episódio da cocaína" para o futuro da psica-

Em primeiro lugar, ressalto desse episódio a sobreposição entre investigação científica e auto-administração; Byck (1974) ressaltou, aliás, como o método da auto-administração foi também adotado por outros pioneiros da pesquisa com drogas psicoativas. Segundo os biógrafos, o uso da cocaína não foi, para Freud, pontual ou casual. Entusiasmava-o tanto a possibilidade de fazer uma grande descoberta quanto encontrar um meio de curar-se de seus males psíquicos e psicossomáticos. A depressão era, em especial, o principal sintoma a ser combatido. Creio que isto comporta conseqüências importantes, e reflete algo que trabalhava no íntimo de Freud. Ora, esta sobreposição de objetivos será reencontrada na sua experiência de auto-análise, ato fundador da psicanálise. E, ainda: ela constituirá um princípio metodológico da nova disciplina: o investigador só poderá avançar na compreensão e no "tratamento" de seu objeto à medida que aprofundar-se no trabalho com o próprio inconsciente. Conforme tem sido bastante ressaltado, esta postura implicou uma ruptura epistemológica em relação ao conceito de ciência da época, calcado na separação rígida entre sujeito e objeto e na crença aferrada na objetividade de uma observação neutra e isenta do próprio olhar do investigador.

É curioso observar, quanto a isto, que mesmo em "Contribuição ao conhecimento da ação da cocaína" - artigo em que ensaiou uma abordagem experimental para lidar com variabilidade de reações no uso da cocaína -, Freud (1985b) tomou a si mesmo como objeto, em um erro básico em qualquer estudo deste gênero.

Eu mesmo me submeti repetidamente a estas duas séries de experimentos. Percebi que tais auto-observações implicam o inconveniente, para as pessoas que a realizam, de requerer dois tipos de objetividade ao mesmo tempo. Tive de proceder dessa maneira por razões alheias a meu controle e porque nenhum dos sujeitos à minha disposição tinha reações regulares à cocaína. (p. 98-99) 
A sua justificativa mal encobre uma racionalização pouco convincente. Sobre a suposta falta de rigor metodológico do trabalho, Jones (1989) comentou que o estudo experimental - e este foi o único trabalho publicado por Freud no gênero -, "não era seu campo efetivo": "todas as idéias são boas, mas os fatos são registrados de maneira algo irregular e sem controle, o que tornaria difícil correlacioná-los com observações de quaisquer outras pessoas" (p. 102).

Se Freud queria fazer uma grande descoberta, não precisaria ter se colocado no lugar de cobaia. Mas o seu desejo o conduziu a buscar um tratamento para si, e para aqueles que o cercavam: Fleischl, Martha, colegas, amigos, familiares e pacientes. A cocaína era apreciada principalmente por seus efeitos terapêuticos: Freud estava mobilizado pelo desejo de curar. O seu desinteresse inicial pela clínica médica ganhava aqui uma revisão: o curar entrou no horizonte de seus anseios mais profundos, ao lado do investigar. E ainda: o curar o outro parecia se entrelaçar com o curar algo em si mesmo. Bem, ao colocar a investigação neste plano reflexivo, Freud pôs em relevo uma dimensão essencial da psicanálise: o fazer experiência. ${ }^{3}$ Praticar a psicanálise é ao mesmo tempo mergulhar na experiência, colocando-se no olho do furacão do acontecer psíquico. É isto que nos ensina o fenômeno da transferência: o material psíquico, ainda que originado em um tempo-espaço longínquo, é reexperimentado ao vivo - condição sine qua non da eficácia do tratamento.

Ora, é difícil imaginar que esta ruptura epistemológica que aqui se anunciava tenha sido fácil, ou que tenha se dado de maneira pacífica e sem conflitos, pois aqui o cientista entra em choque com a tradição em que está inserido, e particularmente com os mestres que a representam. A questão que podemos formular, então, é: esse caráter eminentemente transgressivo de uma nova concepção de ciência não terá se somado, no íntimo de Freud, a outros elementos da cadeia associativa de culpabilidade ligada ao episódio da cocaína? Quem é, afinal, esse novo cientista que ousa colocar-se em primeira pessoa, como sujeito da experiência? Bernfeld (1953) foi, provavelmente, o primeiro a destacar o caráter de "transgressão criativa" no episódio da cocaína já que, pela primeira vez, Freud seguiu o seu próprio caminho; Assoun assinalou, por sua vez, que esta pesquisa de Freud foi seu "primeiro empreendimento sem patrocinador" (apud Rodrigué, 1995 , p. 202). Rodrigué viu em "Sobre a coca" um "componente subversivo" comum a $A$ interpretação dos sonhos: no primeiro se inaugura uma modalidade expositiva típica de Freud - a do observador observado -, acompanhando a tra-

3. Comentei o caráter essencial do fazer experiência para a prática psicanalítica em "Diálogos com Regina Schnaiderman", publicado na Percurso, n. 35, p. 118-119, 2005. 
dição da literatura romântica germânica: "a experiência pessoal como matéria-prima" (p. 202).

Em segundo lugar, chamo a atenção para a busca mítica de uma panacéia para todos os males, e sua relação com a figura do médico. A cocaína foi vista por Freud, inicialmente, como uma droga mágica capaz de curar uma tal diversidade de males que talvez só a sua modéstia científica e o "superego" da comunidade de médicos tenha contido o ímpeto imaginativo de Freud de sugerir mais usos terapêuticos em "Sobre a coca". Mas o tom entusiástico do artigo não deixa dúvidas quanto à infiltração deste mito em sua pesquisa.

Em O estranho caso de dr. Jekyll e Mr. Hyde, ${ }^{4}$ Robert L. Stevenson (1886) retratou brilhantemente esse mito que ronda a figura do pesquisador cientista. $\mathrm{O}$ médico inteligente e cativante que busca fazer uma grande descoberta, isola-se em seu laboratório e inventa uma droga que se auto-administra, despertando reações estranhas e desconcertantes. Ao invés de buscar o auxílio e a mediação dos outros da comunidade - figuras da experiência do senso comum - mergulha cada vez mais em seu projeto. Traz à luz, assim, um outro Eu sinistro que passa paulatinamente a dominá-lo, revelando a face sombria de seu projeto científico: uma dimensão anti-social, selvagem e megalomaníaca de si mesmo até então adormecida. A duplicidade do médico e o monstro já ganhou diversas interpretações psicanalíticas, tais como a da emergência das pulsões primitivas recalcadas ou de um processo dissociativo. ${ }^{5}$ Quando Mr. Hyde entra em ação, estamos certamente diante de um episódio maníaco de origem química, e quando dr. Jekyll "volta" a si após os surtos, podemos reconhecer aquele estado depressivo típico da ressaca do dia seguinte. Assim, não é difícil ver na droga misteriosa retratada por Stevenson uma espécie de cocaína, e reconhecer na via crucis percorrida por Jekyll/Hyde a espiral maligna dos toxicômanos graves. Curiosamente, uma paciente toxicômana de H. Rosenfeld (1960, p. 155) reconheceu-se na história de Jekyll e Hyde ao assistir o filme nela baseado, e identificou-se particularmente com a divisão do Eu em duas personalidades e com a transformação de um "Eu bom" em um "Eu mau" oculto, devido a ação da droga - novamente, o mito da possessão maligna atribuída à droga diabólica.

Mas o foco que aqui nos interessa é a figura do médico/monstro. O médico cientista brilhante e ambicioso pode ser tomado por um ímpeto maligno de origem obscura; o seu aparente engajamento em uma causa para a comunidade

4. O livro foi escrito por Stevenson em três dias, a partir de um sonho, no ano de 1886 - exatamente na mesma época do episódio de Freud com a cocaína!

5. Desenvolvi esta hipótese em "Clínica da dissociação" (Gurfinkel, 2001). 
pode esconder um projeto megalomaníaco e triunfante sobre o outro. Como sabemos, o contraponto deste surto maníaco é a queda depressiva que, quando sobrevém, afoga o sujeito em remorso insuportável. Este ciclo maníaco-depressivo é um dos principais modelos para compreendermos certos quadros de toxicomania (cf. Radó, 1933). Como sabemos, o investimento mágico em um objeto-droga é, nestes casos, motivado por uma forte idealização, que desloca para o objeto os desejos narcísicos de grandiosidade. Será que em algum momento Freud correu o risco de ingressar nesta trilha, quando abraçou apaixonadamente a causa da cocaína? Tudo indica que não; como concluiu Scheidt (1975) em seu cuidadoso estudo, o desenlace da história de Freud com a cocaína atesta exatamente "a solidez de uma constituição psíquica excepcionalmente sadia" (p. 18), afastando qualquer conjetura sobre a morbidez da personalidade de Freud. Ainda assim, não creio ser descabido supor que Freud tenha sido tomado até certo ponto pelo mito do cientista-médico-gênio-louco, em busca da panacéia para todos os males.

A busca da panacéia por meio de uma droga mágica toca ainda em uma questão essencial, que transcende a figura de Freud: a relação complexa do saber médico com as suas drogas. Em trabalho anterior (Gurfinkel, 1996), ao recapitular a história do uso de drogas psicotrópicas na época moderna, abordei tal relação em termos de um feitiço que pode voltar-se contra o feiticeiro:

A história da cocaína pode ser tomada como um exemplo da entrada da droga enquanto objeto na história da ciência. (...) Freud teria enfrentado muitas resistências no meio científico para mostrar que a coca - da qual foi sintetizada a cocaína em 1855 por Gardeke - não era uma "planta divina" mas uma droga. Inicialmente, o discurso médico teria negado o seu efeito farmacológico, sustentando que se tratava de puro imaginário popular. A incorporação da cocaína no discurso médico teria sido paulatina, à medida que alguns autores propuseram o seu uso como anestésico e como droga terapêutica. Parece ter sido necessário que a cocaína fosse colocada na categoria de medicamento para que pudesse ser aceita como droga. (...) O nascimento da toxicomania como objeto do saber médico tem uma certa contemporaneidade em relação ao nascimento da psicanálise, e mais do que isto: esta origem paralela encontra uma enigmática confluência na pessoa de Freud. A relação de Freud com a cocaína é objeto de grande controvérsia entre os seus biógrafos (...).

A incorporação das drogas pelo saber médico teve um duplo aspecto. Por um lado, as drogas psicotrópicas tiveram um grande desenvolvimento farmacológico e têm sido largamente utilizadas no tratamento da "doença mental" ou dos "distúrbios mentais"; neste sentido, estão predominantemente ligadas à psiquiatria. Por outro lado, a medicina toma como objeto o uso não médico das drogas, uso que é considerado um abuso. Surgem então as categorias nosográficas da toxicomania, da dependência de drogas, do hábito, do abuso de drogas etc. Os 
dois aspectos mantêm uma relação estreita, já que o próprio uso das drogas pela medicina facilita enormemente o abuso das mesmas, e é também uma maneira de difusão; o saber médico acaba abrindo caminho - certamente não é esta a sua intenção original - para um tipo de instrumentação da medicação ou "saída" à qual as pessoas podem recorrer em determinadas situações. São mais freqüentes do que normalmente se pensa os casos de dependência às medicações psiquiátricas (ansiolíticos, hipnóticos, anfetaminas anorexígenas, incluindo antipsicóticos e analgésicos narcóticos), situações encobertas que podem ou não incluir um conluio com o médico. Poderíamos dizer, quanto à relação do médico com o seu medicamento/droga, que muitas vezes o feitiço se vira contra o feiticeiro. (p. 28-30)

Como vimos, Freud já tinha consciência, ao dirigir-se à Sociedade Psiquiátrica de Viena, desta dupla pertinência das drogas psicotrópicas ao campo da psiquiatria: enquanto remédio e enquanto "veneno" (devido ao uso indevido, levando ao vício). Mas o que Freud veio a sentir na própria pele, a partir das acusações de Erlenmeyer, foi a sensação repulsiva de ser ele mesmo este "monstruoso médico" que divulgava, defendia e promovia a "terceira praga da humanidade" - um médico-traficante! A sua "droga mágica" parecia ter traído a fidelidade com que inicialmente ele havia a ela se devotado, deixando-o em maus lençóis... Assim, neste feitiço que se volta contra o feiticeiro, a criatura (monstro) voltar-se contra seu criador, o cientista-médico onipotente.

Hoje podemos levantar a hipótese: era esse cientista-médico onipotente que precisava ser tratado e "curado". O resultado dessa cura foi, pelo menos em parte, o nascimento da psicanálise. Aquilo que teve o sabor de um fracasso - como lemos na própria "Autobiografia" - pode ser entendido como um gesto de abertura fundante. Não só a busca da panacéia e de uma cura mágica cai por terra, mas também o projeto de uma cura química para o sofrimento psíquico sofre um forte abalo para Freud. Esta foi uma queda verdadeiramente depressiva, no sentido de um encontro elaborativo consigo mesmo e com os fantasmas infantis onipotentes e triunfantes. Jones sugeriu que o projeto cocaína foi um atalho que trouxe mais sofrimento do que sucesso. Sim, um atalho que procurava evitar o caminho mais árduo do princípio da realidade em detrimento das soluções mágicas; mas Freud aprendeu com a experiência, e não ficou paralisado no sofrimento e na amargura do fracasso - o tom jocoso de sua menção ao fato na "Autobiografia" bem o demonstra.

Anzieu (apud Ocampo, 1988) foi um dos comentadores que melhor captou a importância e o sentido deste "fracasso fértil" de Freud. Pois ele é "o símbolo antecipador do fracasso de todas as drogas e o signo do longo, difícil e inevitável desvio que Freud deverá realizar em si mesmo e com seus pacientes, através de desmontagem dos encadeamentos psíquicos inconscientes" (p. 82). Para Anzieu, esta queda da "onipotência terapêutica" e da "utopia quimioterápica" terá uma 
estação intermediária antes de desaguar na criação do método psicanalítico, a saber: a hipnose e a sugestão. E ainda: ela não será nunca inteiramente perpetuada, pois o fantasma da onipotência terapêutica, da cura mágica ou da panacéia nunca abandonará Freud por completo, cristalizando-se no desejo de curar próprio de todo psicanalista. Assim, com o episódio da cocaína, Freud incorporou de modo verdadeiramente pessoal a tarefa de ser um médico que trata, sem deixar de ser um pesquisador em busca de uma grande descoberta.

\section{Referências}

Abraham, K. (1908). Las relaciones psicologicas entre la sexualidad y el alcoholismo. In: Psicoanálisis clínico. Buenos Aires: Lumen/Hormé, 1994.

Anzieu, D. A auto-análise de Freud e a descoberta da psicanálise. Porto Alegre: Artes Médicas, 1989.

Bernfeld, S. (1953). Freud's studies on cocaine. In: Bick, R. (ed.). Cocaine papers by Sigmund Freud. New York: Meridian, 1975.

BICK, R. (1974). Sigmund Freud and cocaine. In: BICK, R. (ed.). Cocaine papers by Sigmund Freud. New York: Meridian, 1975.

Cesarotto, O. Um affair freudiano: os escritos de Freud sobre a cocaína. São Paulo: Iluminuras, 1989.

Ferenczi, S. (1911a). O papel da homossexualidade na patogenia da paranóia. In: Obras completas. São Paulo: Martins Fontes, 1991. v. 1.

. (1911b). O álcool e as neuroses. In: Obras completas. São Paulo: Martins Fontes, 1991. v. 1.

Freud, S. (1884). On Coca. In: Bick, R. (ed.). Cocaine papers by Sigmund Freud. New York: Meridian, 1975.

. (1885a). Addenda to On Coca. In: BICK, R. (ed.). Cocaine papers by Sigmund Freud. New York: Meridian, 1975.

. (1885b). Contribution to the knowledge of the effect of cocaine. In: BICK, R. (ed.). Cocaine papers by Sigmund Freud. New York: Meridian, 1975.

. (1885c). On the general effect of cocaine. In: BICK, R. (ed.). Cocaine papers by Sigmund Freud. New York: Meridian, 1975.

. (1887). Remarks on craving for and fear of cocaine. In: Bick, R. (ed.). Cocaine papers by Sigmund Freud. New York: Meridian, 1975.

. (1910). El doble sentido antitético de las palabras primitivas. In: Obras completas de Sigmund Freud. Madrid: Biblioteca Nueva, 1981. v. 2. 
. (1924). Autobiografia. In: Obras completas de Sigmund Freud. Madrid: Biblioteca Nueva, 1981. v. 3.

Gay, Peter. Freud: uma vida para nosso tempo. São Paulo: Companhia das Letras, 1989. Gurfinkel, D. A pulsão e seu objeto-droga: estudo psicanalítico sobre a toxicomania. Petrópolis: Vozes, 1996. 2001.

. Do sonho ao trauma: psicossoma e adicções. São Paulo: Casa do Psicólogo,

GutTMACHER, H. (1885). New medications and therapeutic techniques: concerning the different cocaine preparations and their effect. In: Bick, Robert (ed.). Cocaine papers by Sigmund Freud. New York: Meridian, 1975.

Jones, E. A vida e a obra de Sigmund Freud. Rio de Janeiro: Imago, 1989. v. 1.

Ocampo, E.V. Droga, psicoanálisis y toxicomania: las huellas de un encuentro. Buenos Aires: Paidós, 1988.

RAdó, S. (1933). The psychoanalysis of pharmacothymia. Psychoanalytic Quarterly, n. 2, p. 1-23, 1933. Reeimpreso em Yalisove, D.L. (Org.). Essential papers on addiction. New York/London: New York University Press, 1997.

Rodrigué, E. Sigmund Freud: o século da psicanálise. São Paulo: Escuta, 1995. v. 1.

Rosenfeld, H. (1960). Da toxicomania. In: Os estados psicóticos. Rio de Janeiro: Zahar, 1968.

Scheidt, J. vom. As experiências de Freud. Rio de Janeiro: Artenova, 1975.

Stevenson, R.L. (1886). The strange case of Dr. Jekyll and Mr. Hyde. In: Dr. Jekyll and Mr. Hyde and other stories. Ware, Hertfordshire (Great Britain): Wordsworth, 1993.

\section{Resumos}

(El episodio de Freud con la cocaína: el médico y el monstruo)

El objetivo de este trabajo es una evaluación de los posibles "restos" del episodio de Freud con la cocaína en la creación del psicoanálisis, realizada a través de un reexamen retrospectivo, crítico y analítico de ese episodio. El resultado de esa evaluación puso en destaque cuatro elementos: el surgimiento de un Freud psiquiatra y farmacólogo y el abandono gradual de esa vía; el surgimiento de la adicción como objeto de investigación; el modelo de auto-administración como método de investigación; y la creencia y abandono de un proyecto de "curación mágica".

Palabras claves: Freud, cocaína, historia del psicoanálisis, adicciones 
(L'épisode de Freud avec la cocaïne: le médecin et le monstre)

Ce travail porte sur une évaluation des possibles "restes" que l'épisode de Freud avec la cocaïne aurait laissé pour la création de la psychanalyse. Elle a été réalisée à travers le réexamen rétrospectif, critique et analytique de cet épisode. Le résultat de cette évaluation met en relief quatre éléments: le bourgeonnement d'un Freud psychiatre et pharmacologiste et l'abandon progressif de cette voie; le bourgeonnement de la dépendance comme objet de recherche; le modèle de l'auto-administration comme méthode de recherche et l'idée d'un projet de «cure miraculeuse» et son abandon ultérieur.

Mots clés: Freud, cocaïne, histoire da psychanalyse, dépendance

(Freud's episode with cocaine: the doctor and the monster)

The aim of this paper is to evaluate of the possible "remaining portions" of Freud's cocaine episode on the creation of psychoanalysis creation. Specifically, the author provides a critical, analytical and retrospective examination of this episode. The result of the evaluation calls attention to four elements: the appearance of Freud as a psychiatrist and pharmacologist and the gradual abandonment of this path. But addction eventually became an object of research and self-administration was used as a method of research. In addition, the belief in a model of a magical cure was tested and subsequently abandoned.

Key words: Freud, cocaine, psychoanalytical history, addictions

Versão inicial recebida em junho de 2007 Versão aprovada para publicação em julho de 2008

\section{Decio GURFINKEL}

Membro do Depto. de Psicanálise do Instituto Sedes Sapientiae (São Paulo, SP, Brasil) e professor dos cursos de Psicanálise e de Psicossomática no mesmo Instituto; doutor pelo Instituto de Psicologia da Universidade de São Paulo - USP (São Paulo, SP, Brasil) e Pós-doutorando do Programa de Estudos Pós-Graduados em Psicologia Clínica da Pontifícia Universidade Católica de São Paulo - PUC-SP. (São Paulo, SP, Brasil); autor dos livros: Sonhar, dormir e psicanalisar: viagens ao informe (São Paulo: Escuta, no prelo); Do sonho ao trauma: psicossoma e adicções (São Paulo: Casa do Psicaólogo, 2001) e A pulsão e seu objeto-droga: estudo psicanalítico sobre a toxicomania (Petrópolis: Vozes, 1996).

Rua Maranhão, 568/71

01240-000 São Paulo, SP, Brasil

Fone: (11) 3825-9794

e-mail: deciogur@usp.br 